УДК

DOI

\title{
ПРИМЕНЕНИЕ УЛЬТРАЗВУКОВОЙ КАВИТАЦИИ ПРИ ЛЕЧЕНИИ ГНОЙНЫХ РАН ЧЕЛЮСТНО-ЛИЦЕВОЙ ОБЛАСТИ
}

\author{
ОН. Ю. Муратова, И. И. Хасанов, Ш. Ш. Юсупов \\ Ташкентский Государственный стоматологический институт \\ Ташкентская медицинская академия
}

РЕзЮМЕ. В статье приводится обобщение литературных данных, касающихся применения ультразвуковой кавитации в лечении гнойных ран челюстно-лицевой области. Несмотря на значительное количество работ, данные литературы, касающиеся механизма действия ультразвуковой кавитации на биологический объект, довольно отрывочны и не систематизированы, что позволяет ориентировать деятельность практического врача и научные исследования на разработку новых клинических методов применения низкочастотного ультразвука для оптимизации лечения гнойно-воспалительных заболеваний челюстно-лицевой области.

КЛЮЧЕВЫЕ СЛОВА: ультразвуковая кавитация, гнойно-воспалительные заболевания, челюстно-лицевая область.

Вступление. Проблема лечения гнойновоспалительных заболеваний (ГВЗ), несмотря на значительную изученность патогенеза, большое количество используемых медикаментозных средств и способов оптимизации хирургической обработки ран, остается актуальной $[4,7]$.

Поскольку первичная хирургическая обработка ран не обеспечивает полного иссечения некротических тканей и удаления всей раневой микрофлоры, в последнее время получают все большее развитие физические методы совершенствования хирургической обработки гнойных ран $[1,2,4,6,7,13,14]$.

Учитывая низкую адаптационную способность микроорганизмов к физическим факторам воздействия, а также некоторые вызываемые ими эффекты, она стала применяться при гнойных заболеваниях мягких тканей, раневой инфекции, остеомиелите, неспецифических заболеваниях легких, перитоните и др. $[1,2,4,5,8$, $16,17,19,21,23]$.

Показания к применению ультразвуковой кавитации (УЗК) очень широкие - начиная от гнойничковых заболеваний кожи до внутриполостных (надпочечные, поддиафрагмальные, межмышечные, тазовые абсцессы и др.) огромных гнойников $[11,18,20]$.

Влияние ультразвука (УЗ) на биологические системы многогранно и существенно отличается от действия других физических факторов [3, 14, $15,24]$. Основой его биологического действия является способность поглощаться тканями живого организма. Энергия поглощенного УЗ трансформируется в целый ряд биологически активных факторов, важнейшими из которых являются образование тепла, возникновение механических сил, физико-химические превращения. В целом действие УЗ на биологический объект (БО) происходит через акустическую среду (растворы антисептиков, антибиотиков, ферментов, активированной воды и др.), эффективность воздействия зависит от ряда ее физико-химических свойств (плотность, вязкость, звуко- и теплопроводимость, степень дегазации, концентрация и однородность, чистота и др.) $[10,12]$.

Результат реализации основных действующих факторов УЗ через акустическую среду на БО проявляется в виде первичных и вторичных эффектов, а также вторичных лучевых факторов.

Явления, выражающиеся в виде первичных эффектов, характеризуются повышением температуры озвучиваемого раствора, массапереносом и массаобменом, дезинтеграцией микробных клеток, разрывом молекулярной связи и образованием ионов $\mathrm{H}^{+}$и $\mathrm{OH}^{-}$; механическим смещением клеток, изменением геометрического размера различных просветов оболочек клеток, механическим отслаиванием некротизированных тканей, частичным разрывом клеток и фибрилл тканей, проникновением лекарственных средств вглубь ткани и ослаблением сцепления между клеточной оболочкой и содержимым клетки. Первичные эффекты, в свою очередь, приводят к возникновению вторичных эффектов, которые направлены на восстановление нарушенного морфофункционального гомеостаза на различных уровнях организации БО. Так, механическое отслаивание некротизированных тканей способствует их быстрейшему растворению с последующим очищением раны, или дезинтеграция и нарушение оболочки микробных клеток приводит к нарушению и прекращению окисли- 
Огляди літератури, оригінальні дослідження, погляд на проблему

тельно-восстановительных процессов в них с последующим подавлением их жизнедеятельности. Из многочисленных эффектов следует отметить повышение функциональной активности тканевых клеток, ускорение процессов диффузии через клеточные мембраны, стимуляцию лимфо-и кровотока и обмена веществ $[3,14]$, изменение степени оксигенации тканей, нормализацию тканевой и сосудистой проницаемости, стимуляцию репаративного процесса [22], специфических и неспецифических факторов иммунитета $[8,13]$, улучшение реологических свойств крови и микромассаж клеток и тканей. Особо следует отметить положительное влияние УЗ на процессы перекисного окисления липидов при их интенсификации [9].

Изменения, наблюдаемые в озвучиваемой среде, обусловлены как непосредственно действующими факторами УЗ (кавитация, акустические потоки, радиационное действие, переменное движение частиц), так и опосредованными (тепловые, механические, электрические, биологические, биохимические и др.) $[11,24]$.

Реализация прямого и непрямого действия УЗ-колебаний происходит в БО, который, в свою очередь, также обладает целым рядом специфических и неспецифических особенностей, прямо или косвенно влияющих на эффективность воздействия (плотность и вязкость, тепло- и звукопроводимость, оптические и другие биофизические характеристики, степень гидратации и выраженность гнойно-некротических процессов, уровень организации БО и его функциональное состояние). Так, вследствие неоднородности и различной степени гидратации разрушение некротизированных тканей происходит неодновременно и неравномерно.

При озвучивании акустической среды УЗволны вызывают образование кавитации и, как следствие этого, - быстрорастущих парогазовых пузырьков, которые в фазу сжатия мгновенно исчезают. Возникающие при этом ударные волны, электрические разряды и высокие локальные пики температуры инициируют специфические звукохимические реакции в озвучиваемой среде. В гетерогенной среде, помимо существующего общего акустического давления, возникают мелко- и среднемасштабные течения и турбуляции, существенно ускоряющие процессы диффузии, растворения и диспергации веществ.

Неоднородность давления в кавитационном поле приводит к т.н. расшатыванию и разрыву крупных молекул, в результате чего выделяется тепло. Все эти факторы приводят к изменению проницаемости клеточных мембран, возникновению микропотоков внутри клеток, усилению диффузионных и метаболических процессов.

В современной хирургической практике при лечении гнойно-некротических заболеваний мягких тканей широкое применение получила УЗК антисептиками. Ультразвук способствует диффузному проникновению молекул препарата в инерстициальное пространство тканей. Лекарственные вещества проникают в толщу тканей на глубину до 3 см, фармакологическая активность их усиливается, так как после разрушения под влиянием ультразвука макрофагов и тучных клеток остаются продукты распада клеток и медиаторы $[6,7]$.

Механизм бактерицидного действия низкочастотного ультразвука разные авторы объясняют по-разному: повреждением микробной клетки (вплоть до полного ее разрушения) кавитационной волной, повышением температуры среды, в которой распространяются ультраакустические колебания, образованием в воде под влиянием Уз небольших количеств азотной кислоты и перекиси водорода, инактивацией микробных токсинов, изменением под действием Уз коллоидной структуры клеток и проницаемости клеточных мембран $[9,10,14]$.

Основную роль в обеспечении бактерицидности ультразвука играет кавитация. В процессе кавитации в жидкости образуются микроскопические полости. В кавитационных полостях происходят химические реакции, молекулы воды в них диссоциируются на $\mathrm{H}^{+}$и $\mathrm{OH}^{-}$-ионы $[2-5,7]$.

В слое лекарственного вещества развиваются процессы массообмена и массопереноса, что, помимо внедрения лекарственных веществ в ткани, приводит к очистке от гноя, детрита и некротических масс. За счет вибрационного массажа кавитации улучшается кровообращение в зоне воспаления.

Чувствительность к низкочастотному ультразвуку различных микроорганизмов и характер изменений в них зависят от вида микроба, концентрации микробных тел и расстояния между микроорганизмом и источником кавитации $[1,2]$.

Таким образом, Уз-обработка способствует обеспечению полного или частичного подавления действия и развития микробной флоры, интенсивному отторжению некротических тканей и других наслоений, покрывающих раневую поверхность. Этим достигается быстрое развитие регенерации и более глубокое проникновение лекарственных средств в очаг поражения, что увеличивает зону действия препарата. Все это суммарно влияет на организм больного в целом и с учетом стимуляции протекающих в нем физиологических процессов способствует заживлению гнойной раны [22]. 
Огляди літератури, оригінальні дослідження, погляд на проблему

Включение В комплекс лечения Узколебаний низкой частоты положительно отражается на заживлении ран. УЗ низкой частоты обеспечивает более быстрое очищение раны, созревание грануляций и позволяет подготовить рану к закрытию в более ранние сроки. Для низкочастотного ультразвука наиболее характерными являются интенсификация и сокращение во времени 1-й фазы раневого процесса - фазы очищения раны от нежизнеспособных тканей вследствие возрастания протеолитической активности раневого экссудата за счет увеличения в 2,5 раза активности катепсина - одного из основных тканевых протеолитических ферментов [5, 22].

УЗК благоприятно отражается на $\mathrm{pH}$ содержимого гнойной раны - происходит устранение ацидоза в более ранние сроки. УЗ-обработка также способствует значительному уменьшению воспалительно-экссудативных изменений и стимулирует репаративные процессы в ране. Благодаря бактериостатическому и бактерицидному действию после УЗ-обработки реже обнаруживаются колонии микроорганизмов. Нормализуются расстройства в системе микроциркуляторного русла: менее выражены гиперемия, стаз, разрыхление сосудистых базальных мембран, почти не встречаются агрегация эритроцитов и микротромбы, уменьшается проницаемость сосудов и, как следствие, ослабевают явления лимфостаза и отечности тканей [12].

Что касается цитологических особенностей раневой поверхности, то уменьшение бактериальной загрязненности и расстройств микроциркуляции значительно сокращает стадию воспаления и способствует более раннему наступлению стадии пролиферации. Так, грануляционная ткань формируется уже к 5-6 суткам после операции. Увеличивается содержание макрофагов - клеток, играющих ключевую роль в процессе заживления ран. Значительно чаще, чем в контроле, определяются митотически делящиеся фибробласты.

Гистохимические особенности ткани (высокое содержание в цитоплазме и ядрышках фибробластов РНК, наличие вблизи этих клеток метахромазии межклеточного вещества и незрелых аргирофильных коллагеновых волоконец) свидетельствуют об активном синтезе фибробластами кислых гликозаминогликанов и коллагена. В дальнейшем прогрессируют процессы фиброзирования грануляционной ткани и ее эпителизация. При этом васкулиты с лимфоидноплазмоцитарно-макрофагальными инфильтратами встречаются редко, что свидетельствует о менее выраженных иммунопатологических реакциях в ранах, по сравнению с контролем. Почти не встречаются микроабсцессы. Уз-обработка не вызывает патологических реакций в развивающейся соединительной ткани [9].

Выводы. Несмотря на наличие значительного количества работ, данные литературы, касающиеся механизма действия УЗК на биологический объект, довольно отрывочны и несистематизированы, что позволяет ориентировать деятельность практического врача и научные исследования на разработку новых клинических методов применения УЗК для оптимизации лечения гнойно-воспалительных заболеваний чло.

\section{ЛИТЕРАТУРА}

1. Жаров В. П. Применение фотоультразвуковой технологии при лечении инфицированных ран / В. П. Жаров, И. А. Меняев, И. В. Горчак // Мед. тех. 2001. - № 1. - С. 7-12.

2. Зайнутдинов А. М. Применение ультразвуковой кавитации при хирургических инфекциях / А. М. Зайнутдинов // Казанский медицинский журнал. - Вып. 3, Т. 90. - 2009. - С. 42-51.

3. Зубкова С. М. Теоретические основы ультразвуковой терапии / С. М. Зубкова // Физиотерапия, бальнеология и реабилитация. - 2005. - № 3. - С. 3-7.

4. Кисляков В. А. Результаты применения ультразвуковой кавитации в лечении рецидивов язв и гнойно-некротических осложнений синдрома диабетической стопы / В. А. Кисляков // Вестник Российского университета дружбы народов. Серія: Медицина. Вып. 2. - 2010. - С. 25-33.

5. Возможности использования ультразвуковой кавитации при обработке ран в комбустиологии / С. Х. Кичемасов, Ю. Р. Скворцов, И. В. Чмырёв, А. А. Сте-

паненко // Российский научно-практический журнал. Материалы международной конференции, посвященной 60-летию ожогового центра НИИ скорой помощи им. И. И. Джанелидзе «Актуальные проблемы термической травмы». - СПб, 2006.

6. Использование ультразвуковой диссекции и кавитации при лечении глубоких ожогов / С. Х. Кичемасов, Ю. Р. Скворцов, И. В. Чмырёв, А. А. Степаненко // Вестник Российской Военно-медицинской академии. Материалы VIII Всероссийской научно-практической конференции «Актуальные вопросы клиники, диагностики и лечения больных в многопрофильном лечебном учреждении». - СПб, 2007.

7. Митрофанов В. Н. Опыт примнения ультразвуковой кавитации при лечении пациентов с хроническим полостным остеомиелитом / В. Н. Митрофанов, О. П. Живцов // Медицинский альманах. - Вып. 3 (27). - 2013. - С. 25-31.

8. Сологуб Е. Н. Возможность использования низкочастотного ультразвука для коррекции 
Огляди літератури, оригінальні дослідження, погляд на проблему

иммунодефицитных состояний / Е. Н. Сологуб, Л. П. Сизякина, Е. П. Москаленко // Вопр. курортологии, физиотерапии и лечеб. физкультуры. - 1991. №1. - С. 44-46.

9. Состояние интенсивности течения процессов перекисеобразования в ранах в динамике их заживления под воздействием низкочастотного ультразвука и дс-РНК / Л. М. Овсепян, К. Г. Карагезян, С. С. Овакимян [и др.] // Эксперим. и клинич. медицина. - 1990. - Т. 30, № 5. - С. 490-492.

10. Столярж А. Б. Ультразвуковое лечение ран диссектором Sonoca - 180 у пациентов микрохирургического профиля / А. Б. Столярж, О. В. Берлев, А. И. Куленков, Е. В. Галина // Бюллетень деловой информации. - М. : Медицина, 2002.

11. Терапия ультразвуковыми волнами / И. 3. Самосюк, Г. Е. Шимков, Н. В. Чухраев [и др.]. - К. : НМУ «Мединтех», 2003. -173 с.

12. Улащик В. С. Низкочастотный ультразвук: действие на организм, лечебное применение и перспективы исследования / В. С. Улащик // Вопр. курортол., физиотерапии и лечеб. физкультуры. - 2000. - № 6. - С. 3-8.

13. Ухов А. Я. Показатели иммунитета при лечении инфицированных ран низкочастотным ультразвуком / А. Я. Ухов, И. М. Федечко, О. М. Нарепеха // Клинич. хирургия. - 1990. - № 1. - С. 10-12.

14. Физические методы лечения гнойных ран / М. М. Сагатов, Ж. А. Нарчаев, А. Ю. Мурадов, Х. К. Абдурахманов // Биринчи Тошкент Давлат Тиббиет институти Еш Олимларнинг медицина фанининг долзарб муаммоларига багишланган 1998 йил хисобот якунлари илмий анжуманининг илмий маколалари туплами. Тошкент, 1999 йил, 8 январь. -С. 238-240.

15. Ang T. L. Endoscopic ultrasound: moving from diagnostics to therapeutics / T. L. Ang // J. Dig. Dis. - 2008. - Vol. 9 (3). - P. 117-128.

\section{REFERENCES}

1. Zharov, V.P., Menyayev, I.A., \& Gorchak, I.V. (2001). Primeneniye fotoultrazvukovoy tekhnologii pri lechenii infitsirovannykh ran [Application of photo-ultrasonic technology in the treatment of infected wounds]. Med. tekh. - Medical Technology, 1, 7-12 [in Russian].

2. Zaynutdinov, A.M. (2009). Primeneniye ultrazvukovoy kavitatsii pri khirurgicheskikh infektsiyakh [Application of ultrasonic cavitation in surgical infections]. Kazanskiy meditsinskiy zhurnal - Kazan Medical Journal, 3 (90), 42-51 [in Russian].

3. Zubkova, S.M. (2005). Teoreticheskiye osnovy ultrazvukovoy terapii [Theoretical bases of ultrasonic therapy]. Fizioterapiya, balneologiya i reabilitatsiya - Physiotherapy, Balneology and Rehabilitation, 3, 3-7 [in Russian].

4. Kislyakov, V.A. (2010). Rezultaty primeneniya ultrazvukovoy kavitatsii v lechenii retsidivov yazv i gnoynonekroticheskikh oslozhneniy sindroma diabeticheskoy stopy [Results of application of ultrasonic therapy in the treatment of recurrences of ulcers and purulent-necrotic complications of the diabetic foot syndrome]. Vestnik Rossiyskogo universiteta druzhby narodov. Serya: Meditsina.
16. Antisdel J. L. Application of ultrasonic aspirators to endoscopic dacryocystorhinostomy / J. L. Antisdel, M. S. Kadze, R. Sindwani // Otolaryngol. Head Neck Surg. 2008. - Vol. 139 (4). - P. 586-588.

17. High-intensity ultrasound treatment of blunt abdominal solid organ injury: an animal model / C. J. Cornejo, S. Vaezy, G. J. Jurkovich [et al.] // J. Trauma. 2004. - Vol. 57 (1). - P. 152-156.

18. Comparison of harmonic scalpel and highfrequency electrocautery in radial artery harvesting / B Erkut, Y. Unlu, S. Karapolat [et al.] // J. Cardiovasc. Surg. (Torino). - 2008. - Vol. 49 (3). - P. 371-379.

19. High-intensity focused ultrasound for localized thyroidtissue ablation: preliminary experimental animal study / O. Esnault, B. Franc, J. P. Monteil, J. Y. Chapelon // Thyroid. - 2004. - Vol. 14 (12). - P. 1072-1076.

20. Using ultrasonically activated scalpels as major instrument for vessel dividing and bleeding control in minimally invasive video-assisted thyroidectomy / L. Gao, L. Xie, H. Li [et al.] // Zhonghua Wai Ke Za Zhi. - 2003. Vol. 41 (10). - P. 733-737.

21. Hogan M. J. Appendiceal abscess dranaige / M. J. Hogan // Tech. Vasc. Interv. Radiol. - 2003. - Vol. 6 (4). - P. 205-214.

22. Karnes J. L. Continuous therapeutic ultrasound accelerates repair of contraction-induced skeletal muscle damage in rats / J. L. Karnes, H. W. Burton // Arch. Phys. Med. Rehabil. - 2002. - Vol. 83 (1). - P. 1-4.

23. Zahnmed. Treatment of periimplantitiswith laser or ultrasound / F. Schwarz, K. Bieling, A. Sculean [et al.] // Schweiz Monatsschr. - 2004. - Vol. 114. - P. 1228-1235.

24. Design and application of low-frequency ultrasound and its combination with laser radiation in surgery and therapy / V. P. Zharov, Y. A. Menyaev, R. K. Kabisov [et al.] // Crit. Rev. Biomed. Eng. - 2001. Vol. 29. - P. 502-519.

- Journal of the Russian University of Peoples' Friendship. Serya: Medicine, 2, 25-33 [in Russian].

5. Kichemasov, S.Kh., Skvortsov, Yu.R., Chmyrov, I.V., \& Stepanenko, A.A. (2006). Vozmozhnosti ispolzovaniya ultrazvukovoy kavitatsii pri obrabotke ran v kombustiologii [Possibilities of using ultrasonic cavitation in the treatment of wounds in kombustiologii]. Rossiyskiy nauchno-prakticheskiy zhurnal. Materialy mezhdunarodnoy konferentsii, posvyashchennoy 60-letiyu ozhogovogo tsentra NII skoroy pomoshchi im. I.I. Dzhanelidze "Aktualnyye problemy termicheskoy travmy» - Russian Scientific and Practical Journal. Materials of the international conference dedicated to the 60th anniversary of the burn center named by I.I. Dzhanelidze "Actual problems of thermal injury" [in Russian].

6. Kichemasov, S.Kh., Skvortsov, Yu.R., Chmyrov, I.V., \& Stepanenko, A.A. (2007). Ispolzovaniye ultrazvukovoy dissektsii i kavitatsii pri lechenii glubokikh ozhogov [Use of ultrasonic dissection and cavitation in the treatment of deep burns]. Vestnik Rossiyskoy Voyenno-meditsinskoy akademii. Materialy VIII Vserossiyskoy nauchno-prakticheskoy konferentsii «Aktualnyye voprosy kliniki, diagnostiki i leche- 
Огляди літератури, оригінальні дослідження, погляд на проблему niya bolnykh v mnogoprofilnom lechebnom uchrezhdenii» Journal of the Russian Military Medical Academy. Materials of the VIII All-Russian scientific-practical conference "Actual questions of the clinic, diagnosis and treatment of patients in a multi-disciplinary medical institution" [in Russian].

7. Mitrofanov, V.N., Zhivtsov, O.P. (2013). Opyt primeneniya ultrazvukovoy kavitatsii pri lechenii patsiyentov s khronicheskim polostnym osteomiyelitom [Experience of applying ultrasonic cavitation in the treatment of patients with chronic cavitary osteomyelitis]. Meditsinskiy almanakh - Medical Almanac, 3 (27), 25-31 [in Russian].

8. Sologub, Ye.N., Sizyakina, L.P., \& Moskalenko, Ye.P. (1991). Vozmozhnost ispolzovaniya nizkochastotnogo ultrazvuka dlya korrektsii immunodefitsitnykh sostoyaniy [The possibility of using low-frequency ultrasound to correct immunodeficiency states]. Vopr. kurortologii, fizioterapii i lecheb. fizkultury - The Questions of Balneology, Physiotherapy and Treatment Education., 1, 44-46 [in Russian].

9. Ovsepyan, L.M., Karagezyan, K.G., \& Ovakimyan, S.S. (1990). Sostoyaniye intensivnosti techeniya protsessov perekiseobrazovaniya v ranakh v dinamike ikh zazhivleniya pod vozdeystviyem nizkochastotnogo ul'trazvuka i ds-RNK [State of the intensity of the course of peroxidation processes in wounds in the dynamics of their healing under the influence of low-frequency ultrasound and ds-RNA]. Eksperim. i klinich. meditsina - Experimental and Clinical Medicine, 30 (5), 490-492 [in Russian].

10. Stolyarzh, A.B., Berlev, O.V., Kulenkov, A.I., \& Galina, Ye.V. (2002). Ultrazvukovoye lecheniye ran dissektorom Sonoca - 180 u patsiyentov mikrokhirurgicheskogo profilya [Ultrasonic treatment of wounds by Sonoca 180 dissector in microsurgical patients]. Byulleten delovoy informatsii - Journal of Business Information [in Russian].

11. Samosyuk, I.Z., Shimkov, G.Ye., \& Chukhrayev, N.V. (2003). Terapiya ultrazvukovymi volnami [Therapy with ultrasonic waves]. Kiev: NMU «Medintekh» [in Russian].

12. Ulashchik, V.S. (2000). Nizkochastotnyi ultrazvuk: deystviye na organizm, lechebnoye primeneniye i perspektivy issledovaniya [Low-frequency ultrasound: action on the body, therapeutic use and prospects for research]. Vopr. kurortol. fizioterapii i lecheb. Fizkultury - The Questions of Balneology, Physiotherapy and Treatment, 6, 3-8 [in Russian].

13. Ukhov, A.Ya., Fedechko, I.M., \& Narepekha, O.M. (1990). Pokazateli immuniteta pri lechenii infitsirovannykh ran nizkochastotnym ultrazvukom [Immunity indices in the treatment of infected wounds with low-frequency

ultrasound]. Klinich. khirurgiya.- Clinical Surgery, 1, 10-12 [in Russian].

14. Sagatov, M.M., Narchayev, Zh.A., Muradov, A.Yu., \& Abdurakhmanov, Kh.K. (1999). Fizicheskiye metody lecheniya gnoynykh ran [Physical methods of treatment of purulent wounds]. Birinchi Toshkent Davlat Tibbiyet instituti Yesh Olimlarning meditsina fanining dolzarb muammolariga bagishlangan 1998 yil khisobot yakunlari ilmiy anzhumanining ilmiy makolalari tuplami [in Russian].

15. Ang, T.L. (2008). Endoscopic ultrasound: moving from diagnostics to therapeutics., J. Dig. Dis., 9 (3), 117-128.

16. Antisdel, J.L., Kadze, M.S., \& Sindwani, R. (2008). Application of ultrasonic aspirators to endoscopic dacryocystorhinostomy. Otolaryngol. Head Neck Surg., 139 (4), 586-588.

17. Cornejo, C.J., Vaezy, S., Jurkovich, G.J., Paun, M., Sharar, S.R., \& Martin, R.W. (204). High-intensity ultrasound treatment of blunt abdominal solid organ injury: an animal model, J.Trauma, 57 (1), 152-156.

18. Erkut, B., Unlu, Y., Karapolat, S., \& Ugur Kocogullari, C. (2008). Comparison of harmonic scalpel and high-frequency electrocautery in radial artery harvesting. J. Cardiovasc. Surg. (Torino), 49 (3), 371-379.

19. Esnault, O., Franc, B., Monteil, J.P., \& Chapelon, J.Y. (2004). High-intensity focused ultrasound for localized thyroidtissue ablation: preliminary experimental animal study. Thyroid, 14 (12), 1072-1076.

20. Gao, L., Xie, L., Li, H. \& Shao, Y. (2003). Using ultrasonically activated scalpels as major instrument for vessel dividing and bleeding control in minimally invasive videoassisted thyroidectomy. Zhonghua Wai Ke Za Zhi, 41 (10), 733-737.

21. Hogan, M.J. (2003). Appendiceal abscess dranaige. Tech. Vasc. Interv. Radiol., 6 (4), 205-214.

22. Karnes, J.L., \& Burton, H.W. (2002). Continuous therapeutic ultrasound accelerates repair of contractioninduced skeletal muscle damage in rats. Arch. Phys. Med. Rehabil., 83 (1), 1-4.

23. Schwarz, F., Bieling, K., \& Sculean, A. (2004). Treatment of periimplantitiswith laser or ultrasound. Schweiz Monatsschr., 114, 1228-1235.

24. Zharov, V.P., Menyaev, Y.A., \& Kabisov, R.K. (2001). Design and application of low-frequency ultrasound and its combination with laser radiation in surgery and therapy. Crit. Rev. Biomed. Eng., 29, 502-519.

\title{
ЗАСТОСУВАННЯ УЛЬТРАЗВУКОВОЇ КАВІТАЦІї ДЛЯ ЛІКУВАННЯ ГНІЙНИХ РАН ЩЕЛЕПНО-ЛИЦЕВОї ДІЛЯНКИ
}

\author{
๑Н. Ю. Муратова, І. І. Хасанов, Ш. Ш. Юсупов
}

Ташкентський Державний стоматологічний інститут Ташкентська медична академія

РЕЗЮМЕ. У статті наводиться узагальнення літературних даних, що стосуються застосування ультразвукової кавітації в лікуванні гнійних ран щелепно-лицевої ділянки. Незважаючи на значну кількість робіт, дані літератури, 
Огляди літератури, оригінальні дослідження, погляд на проблему

що стосуються механізму дії ультразвукової кавітації на біологічний об'єкт, досить уривчасті і несистематизовані, що дозволяє орієнтувати діяльність практичного лікаря і наукові дослідження на розробку нових клінічних методів застосування низькочастотного ультразвуку для оптимізації лікування гнійно-запальних захворювань щелепно-лицевої ділянки.

КлючОВІ СлОВА: ультразвукова кавітація, гнійно-запальні захворювання, щелепно-лицева ділянка.

\section{APPLICATION OF ULTRASONIC CAVITATION IN TREATMENT OF THE PURIFICATION OF WOUNDS OF THE MAXIMUM-FACE REGION}

@N. Yu. Muratova, I. I. Khasanov, Sh. Sh. Yusupov

Tashkent State Stomatological Institute Tashkent Medical Academy

SUMMARY. The article presents a synthesis of published data relating to the use of ultrasound cavitation in the treatment of purulent wounds of the maxillofacial region. Despite the considerable amount of work, the literature regarding the mechanism of action of ultrasound cavitation on a biological object, rather fragmentary and not systematized, which allows the physician to orient the practical work and research on the development of new clinical methods of application of low-frequency ultrasound to optimize the treatment of inflammatory diseases of the maxillofacial region.

KEY WORDS: ultrasound cavitation; inflammatory diseases; maxillofacial region. 